\title{
PRIMARY URETHRAL ADENOCARCINOMA IN A 68 YEARS OLD FEMALE- A RARE CASE REPORT
}

\author{
Rupesh Gupta1, Sweta Gupta², Ranjit K. Das ${ }^{3}$, Arpan Choudhary4
}

${ }^{1}$ Scholar, Department of Urology, R. G. Kar Medical College, Kolkata, West Bengal.

${ }^{2}$ Senior Resident, Department of Obstetrics and Gynaecology, R. G. Kar Medical College, Kolkata, West Bengal.

3 Professor and HOD, Department of Urology, R. G. Kar Medical College, Kolkata, West Bengal.

${ }^{4}$ Scholar, Department of Urology, R. G. Kar Medical College, Kolkata, West Bengal.

\begin{abstract}
BACKGROUND

Urethra is one of the rarest sites of malignancy in the female, which accounts for approximately $0.02 \%$ of all cancers in a female. The male is two times more commonly affected than female. Primary adenocarcinoma of female urethra is very rare. Only a few retrospective cases have been reported in the literature. Most of the patients are symptomatic at the time of presentation and haematuria is the most common symptom. We are reporting a rare case of an enteric type of urethral adenocarcinoma in a 68year-old female who was presented with caruncle like mass protruding through the urethra and diagnosed retrospectively. Distal urethrectomy was performed to achieve complete clearance. The patient is continent and doing well in 18 months of followup. Urethral cancer, though they are rare but should be considered as differential diagnosis of any urethral mass.
\end{abstract}

\section{KEYWORDS}

Urethral Cancer; Adenocarcinoma; Female; Caruncle.

HOW TO CITE THIS ARTICLE: Gupta R, Gupta S, Das RK, et al. Primary urethral adenocarcinoma in a 68 years old female- a rare case report. J. Evolution Med. Dent. Sci. 2017;6(26):2208-2210, DOI: 10.14260/Jemds/2017/476

\section{BACKGROUND}

Urethral cancer comprises less than $1 \%$ of genitourinary malignancy in female.[1] Male has preponderance to female in the ratio of 2:1.[2] Squamous cell carcinoma is the most common histological type (70\%) and adenocarcinoma is relatively uncommon (about 10\%).[3] MRI is helpful for staging and to detect the presence of enlarged lymph nodes.[1] The biopsy is essential for definitive diagnosis. Treatment guideline for urethral cancer is not very clear due to less research and prospective studies owing to the rarity of the disease. Treatment depends on the location and stage of the tumour.[1]

\section{CASE REPORT}

A 68-year-old post-menopause female presented to urology outdoor with complaints of a mass protruding through urethral opening and obstructive voiding for last 2 months. There was no history of haematuria, urinary tract infection and surgery. General examination was unremarkable. On local examination, a papillary growth of about $2 \mathrm{~cm} \times 1.5 \mathrm{~cm}$ was protruding from the urethral orifice. The provisional diagnosis of urethral caruncle was made and planned of excision of the same. Blood biochemistry, urine analysis and urine culture were essentially normal. Excision of urethral growth was done under regional anaesthesia.

Histopathology (HPE) report came as welldifferentiated, the enteric type of adenocarcinoma [Figure 1a and $1 \mathrm{~b}$ ]. MRI pelvis and whole abdomen, chest x-ray and liver function test were done to stage the tumour and planning for further

Financial or Other, Competing Interest: None.

Submission 30-01-2017, Peer Review 19-03-2017,

Acceptance 24-03-2017, Published 30-03-2017.

Corresponding Author:

Dr. Rupesh Gupta,

Department of Urology,

R. G. Kar Medical College,

Khudiram Bose Sarani,

Kolkata-700004, West Bengal.

E-mail: drrupesgupta@gmail.com

DOI: $10.14260 /$ jemds $/ 2017 / 476$

\section{(c) (i) $\$$}

management. MRI had shown a small ill-defined, altered signal intensity area involving the distal urethra with maintained fat plane with adjacent structure [Figure 2]. Chest $\mathrm{x}$-ray and LFT were within normal limits.

Distal urethrectomy was done to achieve complete removal of the tumour. Fortunately, HPE report did not reveal any residual tumour. In followup, 3 monthly cystourethroscopy and 6 monthly MRI pelvis and chest x-ray have been done. The patient was continent and no recurrence or metastasis seen in 18 months of close followup.

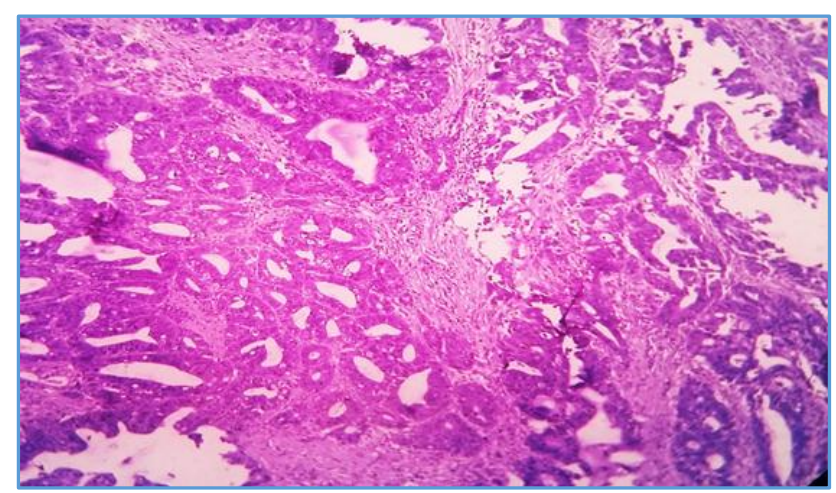

Figure 1a. (10X Magnification)

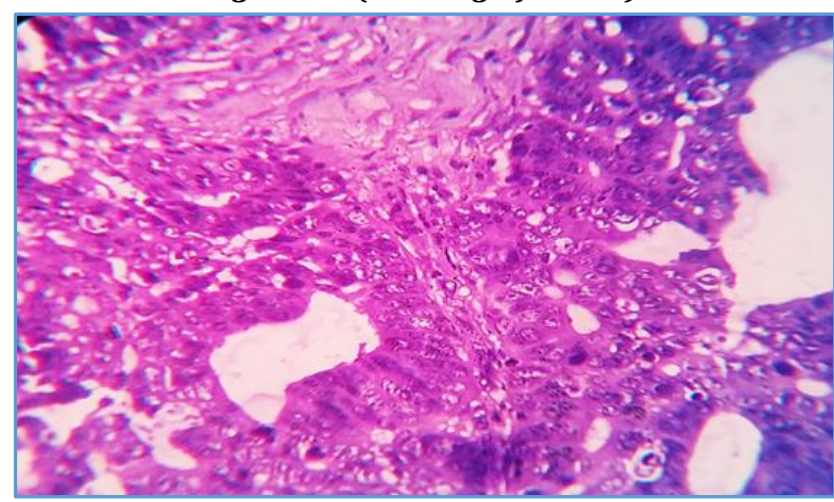

Figure $1 b$ (40X Magnification)

Figure 1a and 1b. Low Magnification Images showed Adenocarcinoma of Urethra (Enteric Type) \{Haematoxylin \& Eosin (H\&E) Stain) 


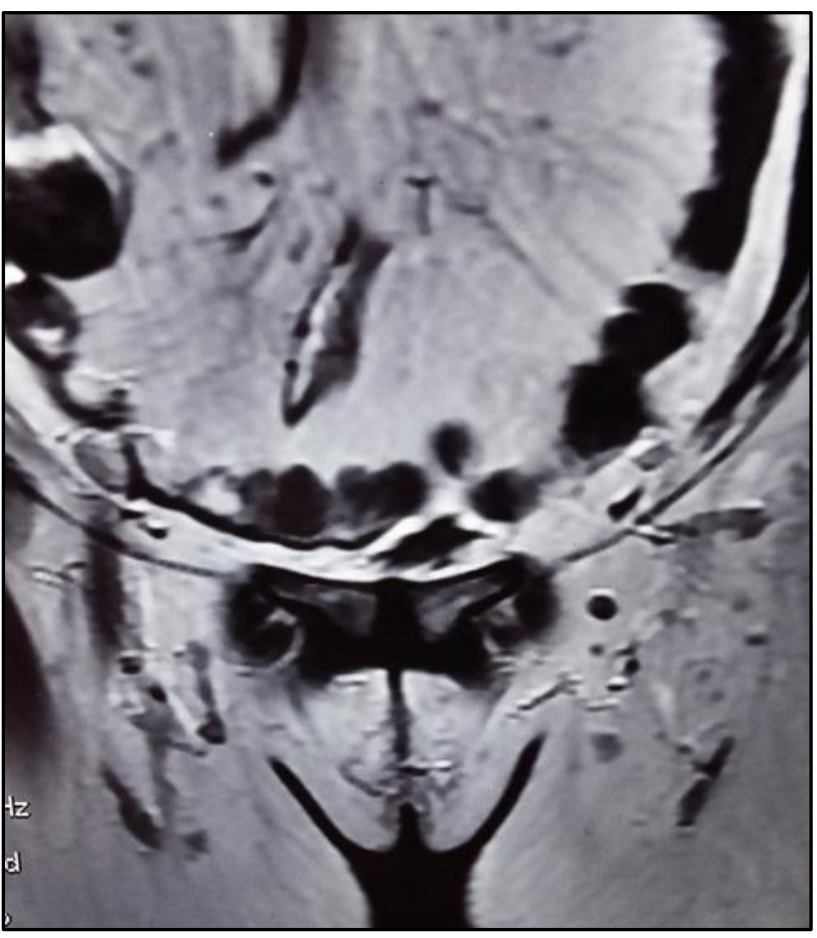

Figure 2. T2-Weighted MRI Coronal Section of Pelvis showed an Altered Intensity Area in Distal Urethra at the Level of Vaginal Vault with Maintenance of Adjacent Fat Planes

\section{DISCUSSION}

Primary Urethral cancer is a rare type of malignancy, which accounts for about $0.02 \%$ of all female cancers and $<1 \%$ of all genitourinary cancer in female.[1] Less than 2000 total cases of urethral cancers have been reported in the literature. ${ }^{[4]}$ According to recent SEER data based study; the male is 2 times more commonly affected than female.[2] Most of the patients diagnosed in 5th and 6th decades of life.[1] Although, there is no definitive causative factor identified, but many aetiological factors have been postulated like chronic irritation, leukoplakia, urethral diverticulum, caruncle, polyps and human papillomavirus or other viral infection.[1] In our case, caruncle may be the causative factor. Squamous cell carcinoma accounts for about $70 \%$ of urethral cancers in a female. Transitional cell carcinoma (20\%) and adenocarcinoma (10\%) are next common variant. [3] Other uncommon histological types are lymphoma, sarcoma, melanoma, neuroendocrine tumour and metastasis. Most common cancer in urethral diverticulum is adenocarcinoma (60\%).[1] Urethral adenocarcinoma can be either enteric or colloidal or signet ring histology.[1] HPE in our case was an enteric type of adenocarcinoma.

At the time of presentation, more than half of the patients of primary urethral cancer have symptoms of advanced disease. Symptoms include visible haematuria or bloody urethral discharge (62\%), extraurethral mass (52\%), obstructive voiding (48\%), pelvic pain (33\%), urethrocutaneous fistula $(10 \%)$ or dyspareunia.[5] Over the time, the urethral mass may protrude from urethral meatus or spread locally to the anterior vaginal wall and proximally to proximal urethra or bladder. Palpable lymph nodes present in $30 \%$ of the patients of urethral cancer, which is more common in advanced urethral cancer. Haematogenous metastasis is rare; lung, liver, bone and brain are the sites in decreasing order of frequency.[6] Our patient was presented with per urethral protruding mass and obstructive voiding. Female with urethral cancer should be evaluated by detailed history, urine for cytology, cystourethroscopy, examination under anaesthesia, radiological imaging like CT/MRI of pelvis and abdomen and chest x-ray.[7] MRI provides best anatomical details of tumour extensions and lymph nodes involvement. In MRI, urethral lesions appear hypointense on T1-weighted image and hyperintense on $\mathrm{T} 2$ weighted image. HPE is necessary for definitive diagnosis. No definite protocol for treatment and followup of urethral cancer due to the scarcity of cases and heterogenicity of disease. Treatment is individualised and depends on the location and stage of the tumour.[1] Tumour at distal urethra, especially small and superficial tumour can be treated with local excision which provides a good functional outcome. Advanced and proximal urethral tumours require more extensive surgery like anterior pelvic exenteration with lymphadenectomy. Radiotherapy or chemotherapy have a role in neoadjuvant or adjuvant setting. A recent trend is towards the use of multimodal therapy, especially in late stage tumours.[1] Our patient had localised tumour at the distal urethra and distal urethrectomy was performed.

Recent survival analysis suggests that squamous cell cancer has more cancer specific survival than urothelial or adenocarcinoma (hazard ratio of 2.03 and 1.90, respectively).[1] Prognosis of distal urethral cancer is usually better than a proximal tumour; 5-year survival, disease specific survival rate is $71 \%$ for distal lesions, $48 \%$ for proximal lesions and $24 \%$ for lesions involving the majority of urethra. ${ }^{[8]}$ Factors for the worse prognosis are advanced age, African-Americans, non-squamous histology, advanced stage and presence of lymph nodes at the time of presentation.[7]

\section{CONCLUSION}

Primary urethral adenocarcinoma in a female is very uncommon. It should be considered as differential diagnosis of any urethral mass. MRI is useful radiological investigation and biopsy is essential for definitive diagnosis. Treatment is individualised and varies from local excision to anterior pelvic exenteration with lymphadenectomy with or without chemoradiotherapy. Survival is usually better for distal and early stage tumours.

\section{REFERENCES}

[1] Sharp DS, Angermeier KW. Tumors of the urethra. In: Wein AJ, Kavoussi LR, Novick AC, et al. eds. CampbellWalsh Urology. $11^{\text {th }}$ edn. Philadelphia, USA: Saunders 2016:885-6.

[2] Swartz MA, Porter MP, Lin DW, et al. Incidence of primary urethral carcinoma in the United States. Urology 2006;68(6):1164-8.

[3] Ouzaid I, Hermieu JF, Dominique S, et al. Management of adenocarcinoma of the female urethra: case report and brief review. Can J Urol 2010;17(5):5404-7.

[4] Guidos J. Urethral cancer: background, history of the procedure, problem. 2013 Emedicine. medscape. com. http://emedicine.medscape.com/article/451496overview. 


\section{Jemds.com}

[5] Gheiler EL, Tefilli MV, Tiguert R, et al. Management of primary urethral cancer. Urology 1998;52(3):487-93.

[6] Karnes RJ, Breau RH, Lightner DJ. Surgery for urethral cancer. Urol Clin North Am 2010;37(3):445-57.

[7] Gakis G, Witjes JA, Compérat E, et al. Guidelines on primary urethral carcinoma. European Association of Urology, 2015.

\section{Case Report}

[8] Dalbagni G, Zhang ZF, Lacombe L, et al. Female urethral carcinoma: an analysis of treatment outcome and a plea for a standardized management strategy. Br J Urol 1998;82(6):835-41. 